\title{
Effect of LH-Releasing Hormone on Gonadal Development in a Salmonoid fish, the Ayu
}

\author{
Katsumi AIDA* \\ (Accepted September 8, 1982)
}

\begin{abstract}
Maturing ayu fish at early vitellogenic or early spermatogenic stages received a single intraperitoneal (IP) injection of emulsified synthetic LH-RH $(0,50$ or $500 \mu \mathrm{g})$ at the start of the experiment and were reared under a gonad-suppressive photoperiod (16L-8D) for 20 days. Gonadal atrophy occurred in the control and $50 \mu \mathrm{g} \mathrm{LH}-\mathrm{RH}$ treated groups. However, $500 \mu \mathrm{g} \mathrm{LH}-\mathrm{RH}$ remarkably accelerated gonadal development despite the suppressive photoperiod. All males discharged a large amount of seminal fluid, and 3 of 4 females ovulated. The gonadotrophs of the group treated with $500 \mu \mathrm{g} \mathrm{LH}-\mathrm{RH}$ were hypertrophied and degranulated. In the control and $50 \mu \mathrm{g} \mathrm{LH}-\mathrm{RH}$ treated groups, the gonadotrophs were small and irregular and contained numerous small granules along with some larger ones.

Immature ayu at pre-vitellogenic or pre-spermatogenic stages received a single IP injection of emulsified $\mathrm{LH}-\mathrm{RH}(0,50$ or $500 \mu \mathrm{g})$ on day 1 and 20 of a 40-day exposure to a gonad-suppressive photoperiod (16L-8D). Gonadal development failed to occur in any of the groups. The gonadotrophs from all groups were similarly inactive.

These results indicate that synthetic mammalian LH-RH cannot initiate gonadotropin synthesis in undeveloped gonadotrophs of immature fish, whereas large amounts are able to stimulate not only the release but also the synthesis of gonadotropin in the developed gonadotrophs of maturing fish.
\end{abstract}

It was ascertained that synthetic mammalian LH-RH could induce the secretion of gonadotropin in teleosts. ${ }^{1-b}$ ) But the high level of plasma gonadotropin did not last for a long period, since the decapeptide was decomposed rapidly in the blood. In some species, ovulation was induced with a single or several administrations of an aqueous solution of $\mathrm{LH}-\mathrm{RH}^{\left.{ }^{8-10}\right)}$ In the flounder and goby, ${ }^{10}$ ) the administration of an aqueous solution of LH-RH failed to induce ovulation, but with emulsified LH-RH it was highly effective. These results suggest that emulsion of LH-RH is more effective in inducing ovulation than aqueous solution probably by the gradual absorption of emulsion for a long period. In general, it takes longer time for the accomplishment of vitellogenesis or spermatogenesis than that of ovulation in teleosts. Therefore, it seems difficult to induce gonadal development in teleosts with a single administration of an aqueous solution of LH-RH. In fact, the ovarian maturation was induced in the medaka, Oryzias latipes, ${ }^{10)}$ with twelve injections of an aqueous solution of LH-RH for a period of 6 weeks.

In a previous experiment, ${ }^{\theta)}$ a single administra- tion of emulsified LH-RH was effective at least for 10 days. Therefore, this method seems to be effective in inducing vitellogenesis or spermatogenesis with a few administrations. In the present study, I tried to induce the vitellogenesis and spermatogenesis of a salmonoid fish, the ayu, Plecoglossus altivelis, under the suppressive photoperiod (16L-8D) with the emulsified LH-RH. The ayu has a life span of one year and its gonadal maturation is accelerated under the short day length, whereas it is suppressed under the long day length. ${ }^{11)}$

\section{Material and Methods}

Juvenile ayu were brought from Lake Biwa in Shiga Prefecture and reared at the Fisheries Laboratory, The University of Tokyo in Sizuoka Prefecture. Two experiments were undertaken using maturing fish (Experiment 1) and immature fish (Experiment 2).

In Experiment 1, fish were reared under the natural day length (accelerative phtoperiod for gonadal development from the end of July) until the start of the experiment (August 30). At

* Laboratory of Fish Physiology, Faculty of Agriculture, The University of Tokyo, Bunkyo-ku, Tokyo 113, Japan（会田勝美：東京大学费学部)。 
Table 1. Effect of LH-RH on gonadal development in a salmonoid fish, the ayu, under the suppressive photoperiod (16L-8D)

\begin{tabular}{|c|c|c|c|c|c|c|}
\hline Experiment & Sex & Treatment & $\begin{array}{l}\text { No. of Fish } \\
\text { Examined }\end{array}$ & $\begin{array}{l}\text { Average of } \\
\text { Body Weight } \\
\text { (g) }\end{array}$ & $\begin{array}{c}\text { Gonado- } \\
\text { somatic } \\
\text { Index }(\%)^{* 1}\end{array}$ & $\begin{array}{c}\text { No. of } \\
\text { Ovulated or } \\
\text { Spermiated } \\
\text { fish }\end{array}$ \\
\hline \multirow{10}{*}{ I } & \multirow{5}{*}{ Male } & Initial control & 5 & 16.3 & $2.5 \pm 0.6$ & 0 \\
\hline & & Control & 7 & 16.2 & $2.1 \pm 0.5$ & 0 \\
\hline & & LH-RH $50 \mu \mathrm{g}$ & 6 & 16.6 & $2.1 \pm 0.8$ & 3 \\
\hline & & LH-RH $500 \mu \mathrm{g}$ & 5 & 16.5 & $7.8 \pm 2.3^{* 2}$ & 5 \\
\hline & & Natural day length & 6 & 15.6 & $6.9 \pm 0.7^{* 3}$ & 3 \\
\hline & \multirow{5}{*}{ Female } & Initial control & 4 & 15.8 & $2.6 \pm 0.3$ & 0 \\
\hline & & Control & 8 & 17.1 & $3.0 \pm 0.8$ & 0 \\
\hline & & LH-RH $50 \mu \mathrm{g}$ & 6 & 13.9 & $3.7 \pm 2.1$ & 0 \\
\hline & & LH-RH $500 \mu \mathrm{g}$ & 4 & 20.4 & $31.7 \pm 3.6^{* 8}$ & 3 \\
\hline & & Natural day length & 6 & 14.9 & $11.3 \pm 1.8^{* 8}$ & 0 \\
\hline \multirow{6}{*}{ II } & \multirow{3}{*}{ Male } & Control & 9 & 13.2 & $0.04 \pm 0.004$ & 0 \\
\hline & & LH-RH $50 \mu \mathrm{g}$ & 7 & 14.8 & $0.04 \pm 0.003$ & 0 \\
\hline & & LH-RH $500 \mu \mathrm{g}$ & 3 & 18.6 & $0.03 \pm 0.002$ & 0 \\
\hline & \multirow{3}{*}{ Female } & Control & 1 & 8.8 & 0.65 & 0 \\
\hline & & LH-RH $50 \mu \mathrm{g}$ & 3 & 12.7 & $0.52 \pm 0.02$ & 0 \\
\hline & & LH-RH $500 \mu \mathrm{g}$ & 4 & 13.5 & $0.64 \pm 0.05$ & 0 \\
\hline
\end{tabular}

that time, fish were at the early vitellogenic or spermatogenic stages (see initial control in Table 1). Fish were divided into 4 groups, 3 of which received a single intraperitoneal (IP) injection of emulsion $(0.1 \mathrm{ml})$ containing 0,50 and $500 \mu \mathrm{g}$ of LH-RH at the start of the experiment. After the injection, fish were moved to the covered indoor tanks $(1 \times 2 \mathrm{~m})$ which were illuminated for 16 hours (suppressive phtoperiod) with a $40 \mathrm{~W}$ fluorescent lamp. A remaining group was reared in a outdoor tank $(1 \times 4 \mathrm{~m})$ under the natural day length without LH-RH injection. Each group was reared for 20 days. LH-RH was dissolved in $0.8 \% \mathrm{NaCl}$ and was emulsified with an equal volume of Freund incomplete aduvant (Iatron Lab.).

In Experiment 2, immature fish which were at the pre-vitellogenic or pre-spermatogenic stages under the suppressive photoperiod (16L-8D), were used. Fish were divided into 3 groups, which received IP injections of emulsion $(0.1 \mathrm{ml})$ containing $0,50,500 \mu \mathrm{g}$ of LH-RH both at the start and 20th day, and reared for 40 days under the same suppressive photoperiod in the indoor tanks $(1 \times 2 \mathrm{~m})$. All tanks were supplied with running water $\left(25^{\circ} \mathrm{C}\right)$.

At the end of the experiment, tissues were fixed with Zenker-formol and Bouin, and embedded in paraffin. Sections were cut to 4 or $\mathbf{1 0}$ micra and were stained with Mayer's hematoxylin-eosin. Pituitary gland was fixed with $2.5 \%$ glutaraldehyde $-2 \%$ parafolmaldehyde in $0.1 \mathrm{M}$ cacodylate buffer ( $\mathrm{pH} 7.5$ ) and post fixed with $1 \%$ osmic acid in the same buffer. After dehydration, the tissue was embedded in Epon 812. Sections were cut on a LKB ultramicrotome. Thick sections were stained with aldehydethionin-PAS, Azan and toluidine blue. Thin sections were stained with uranyl acetate and lead citrate. Observation was carried out on a Hitachi HU-12 electron microscope.

\section{Results}

\section{Gonad}

The results were summarized in Table 1. In the Experiment 1, gonadal development of the control group ceased under the suppressive phtoperiod (16L-8D). In the testis, spermatogonia at the mitotic stage, spermatocytes and spermatids completely disappeared, whereas spermatozoa were still present as illustrated in Plate I-1. In the ovary, degenerative features were found in the cytoplasm of the oocytes as shown in Plate I-5. Gonadal development stopped in many individuals in the group treated with $50 \mu \mathrm{g}$ of 
emulsified LH-RH. But spermiation was recognized in 3 out of 6 males and normal development of the ovary was found in 1 out of 6 females. On the other hand, gonadal development was highly accelerated in the group treated with $500 \mu \mathrm{g}$ of emulsified LH-RH. All the males discharged a large amount of seminal fluid. The spermatogenesis was at the peak in most male fish as shown in Plate I-2. Others already exhausted almost all spermatozoa, whereas spermatogenesis was still continuing as shown in Plate I-3. In females, the vitellogenesis was remarkably accelerated and 3 out of 4 females had already ovulated (Plate I-7). In both sexes, gonadosomatic indices were significantly higher than those of the control. In the group which was reared under the natural day length without LH-RH injection, gonad showed a normal development (Plate I-4 and 8). But gonadosomatic indices of both sexes were lower than those of treated group with $500 \mu \mathrm{g}$ of emulsified LH-RH.

In Experiment 2, gonadal development was not induced in all treated groups. In the testis, mitotic increase of spermatogonia was not recognized as illustrated in Plate II-9 and 10. Oocyte were still at the non-yolky stage (perinucleolus stage) in all groups.

\section{Gonadotroph}

The gonadotrophs of ayu were situated at the ventro-lateral region of proximal pars distails (PPD). In Experiment 1, gonadotrophs of the control group became small and showed irregular shape, but still had two types of secretory granules which were several large granules (1-2 $\mu$ ) and numerous small granules $(100-500 \mathrm{~nm})$ as shown in Plate II-13. Expanded vesicular rER were present in small numbers. The gonadotrophs in the group treated with $50 \mu \mathrm{g}$ of emulsified LHRH showed almost same activity as found in the control. On the other hand, PPD in the group treated with $500 \mu \mathrm{g}$ emulsified LH-RH was remarkably hypertrophied in comparison with that in the control group (Plate II-11 and 12). Almost all gonadotrophs were highly hypertrophied and had a hypertrophied nucleus and distinct nucleolus. Therefore, enlargement of PPD seems to be induced by the hypertorphy of the gonadotrophs. Hypertrophied gonadotrophs markedly degranulated and had many vesicular rER and well developed Golgi apparatus as shown in Plate II-14 and 15. Cytoplasm showed week affinity for dyes. In some gonadotrophs, small granules remained at the periphery of the cyto- plasm and became smaller $(100-250 \mathrm{~nm})$ than those of the control. Large granules were still present in some cells. Electron dense substances were recognized in Golgi lamellae and vesicles. The gonadotrophs of the group reared under natural photoperiod without LH-RH administration were hypertrophied, but still possessed numerous small granules and a few large granules in the cytoplasm.

In Experiment 2, the gonadotrophs in all groups were small and undeveloped. Golgi apparatus and rER were also undeveloped. Secretory granules were scarcely recognized in the cells of all groups.

\section{Discussion}

In Experiment 1, the spermatogenesis and vitellogenesis were completely suppressed in the control group under the photoperiod of $16 \mathrm{~L}-8 \mathrm{D}$, whereas a single administrations of $500 \mu \mathrm{g}$ emulsified LHRH succeeded in accelerating the gonadal development in both sexes under the same suppressive photoperiod. This indicates that synthetic mammalian LH-RH can stimulate the gonadotropin secretion in maturing ayu, and a single injection of emulsified LH-RH is effective for 20 days. In the medaka, twelve injections of an aqueous solution were undertaken to induce gonadal development. The gonadal development was more rapid in the group treated with $500 \mu \mathrm{g}$ of emulsified LH-RH than in the group reared under the natural day length. The result suggests that the amount of gonadaotropin releasing hormone is one of the factors which regulate the speed of gonadal development.

Ovulation inducing effect of LH-RH was already reported in several species of teleosts. ${ }^{\theta-10}$ ) In the present study, all males discharged a large amount of seminal fluid and 3 of 4 females ovulated. Therefore, it is concluded that mammalian LH-RH is able to control both processes of vitellogenesis and ovulation in the female, and spermatogenesis and spermiation in the male.

Gonadotrophs in the fish treated with $500 \mu \mathrm{g}$ of LH-RH, showed hypertrophied cell body, enlarged nucleus, distinct nucleolus, degranulation, proliferation of vesicular rER and well developed Golgi apparatus. These histological changes indicate that $\mathrm{LH}-\mathrm{RH}$ can induce not only the release, but also synthesis of gonadotropin.

In Experiment 2, LH-RH administration was unscccessful in inducing the gonadal develop- 
ment. This is an interesting phenomenon and undeveloped gonadotrophs indicate that mammalian LH-RH can not induce gonadotropin syntheis in immature fish reared under the suppressive photoperiod. This result suggests three possibilities, 1) mammalian LH-RH is not able to initiate the gonadotropin synthesis (in fact, it is suggested that gonadotropin releasing hormone in teleosts chemically differes from mammalian LH-RH), 2) Simultaneous stimulation of LH-RH with other factor(s) (e.g. monoamines or steroids $^{12,13)}$ is necessary for the initiation of gonadotropin synthesis, and 3) suppressive substance is present in immature fish. LH-RH stimulated the gonadotropin synthesis in immature medaka ${ }^{10)}$ under the suppressive photoperiod. This is the reverse of our result obtained in immature ayu fish. The medaka used in that study, was about 2 years old adult which probably had laid eggs at the last spawning season. Such immature individuals probably have mature type of gonadotrophs, which may respond to LH-RH under the suppressive photoperiod. Since the ayu has a life span of one year, immature fish has never laid eggs and has undeveloped gonadotrophs, which may not respond to mammalian LH-RH.

In fishes, it is not ascertained whether there is only one cell type or two cell types in the gonadotrophs like LH and FSH cells in mammals. Gonadotrophs showed the same histological changes following the administration of $\mathbf{L H}$ RH in Experiment 1. This suggests that the ayu has one type of gonadotroph. But the conclusion derived from the present study is presently considered tentative. To elucidate this result further, we are studying on the cytological changes of gonadotrophs of ayu at different physiological states.

\section{References}

1) B. Breton and C. Weil: C. A. Acad. Sci., Ser. D, 277, 2061-2064 (1973).

2) C. Weil, B. Breton and P. Reinald: $C . R$. Acad. Sci., Ser. D, 280, 2469-2472 (1975).

3) L. W. Crim and D. M. CluetT: Endocrinol. Res. Commun., 1, 101-110 (1974).

4) L. W. Crim, R. E. Peter and R. Billard: Gen. Com. Endocrinol. 30, 77-82 (1976).

5) R. E. Peter: Can. J. Zool., 58, 1100-1104 (1980).

6) K. Hirose: Bull. Japan. Soc. Sci. Fish., 40, 12351240 (1974).

7) T. J. Lam, S. Pandy and W. S. Hoar: Can. J. Zool., 53, 1189-1192 (1975).

8) Cooperative team for Hormonal application IN Pisciculture: Sci. Sinica, 20, 469-474 (1977).

9) K. Aida, S. Izumo, H. Satoh and T. Hibiya: Bull. Japan. Soc. Sci. Fish., 44, 445-450 (1978).

10) K.S.K. Chan: Can. J. Zool., 55, 155-160 (1977).

11) Y. Shiraishi and T. TAKeda: Bull. Freshwater Fish. Res. Lab., 11, 69-81 (1961).

12) L. W. Crim and D. M. Evans: Gen. Comp. Endocrinol, , 37, 192-196 (1979).

13) L. W. Crim, R. E. Peter and R. Billard: Gen. Endocrinol., 44, 374-381 (1981). 


\section{Explanation of Plates}

Plate 1-1. Testis in the control of Experiment 1. The spermatogenesis completely stopped but spermatozoa(s) are still remaining in the seminiferous lobules. $\times 240$

2. Testis of the fish treated with $500 \mu \mathrm{g}$ of emulsified LH-RH in Experiment 1, showing active spermatogenesis. sg, spermatogonium; sc, spermatocyte; st, spermatid. $\times 240$.

3. Testis of the fish treated with $500 \mu \mathrm{g}$ of emulsified LH-RH in Experimet 1. Almost all spermatozoa(s) are already discharged. $\times 240$

4. Testis of the fish reared under the natural day length, showing a normal development. $\times 240$

5. Ovary of the control in Experiment 1. Degenerative features (arrows) are found in the cytoplasm of yolky oocytes. $\times 240$

6. Ovary of the fish treated with $50 \mu \mathrm{g}$ of LH-RH in Experiment 1, showing the same degeneration (arrows) as found in the control. $\times 240$

7. Ovary of the fish treated with $500 \mu \mathrm{g}$ of LH-RH in Experiment 1, Ovulated ocyte(o) and empty follicules (arrows) are observed. $\times 60$

8. Ovary of the fish reared under the natural day day length, showing normally developed occytes. $\times 180$

Plate I-9. Testis of the control in Experiment 2. $\times 240$

10. Testis of the fish treated with $500 \mu \mathrm{g}$ of LH-RH in Experiment 2, showing the same undeveloped feature as found in the control. $\times 240$

11. Longitudinal section of the pituitary gland in the control of Experiment 1. RPD, rostral pars distalis; PPD, proximal pars distalis; PI, pars intermedia. $\times 33$

12. Longitudinal section of the pituitary gland treated with $500 \mu \mathrm{g}$ of $\mathbf{L H}-\mathrm{RH}$ in Experiment 1 , showing a hypertrophied proximal pars distalis (PPD). $\times 33$

13. Fine structure of the gonadotroph (GTH) in the control of Experiment 1. A few large granules $(\mathrm{Lg})$ and numerous small granules $(\mathrm{Sg})$ are recognized. STH, somatotroph; ER, rough-surfaced endoplasmic reticulum. $\times 7500$

Plate III-14. Fine structure of the gonadotroph (GTH) of male fish treated with $500 \mu \mathrm{g}$ of LHRH in Experiment 1. Almost all small granules $(\mathrm{Sg})$ were discharged, and granules are smaller than those of the control. STH, somatotroph; TSH, thyrotroph; Lg, Large granules $\mathrm{M}$; mitochondria; G, Golgi apparatus. $\times 7500$

15. Fine structure of the hypertrophied gonadotroph of the female fish treated with $500 \mu \mathrm{g}$ of $\mathbf{L H}-\mathrm{RH}$ in Experiment 1. Small granules were dischared and Golgi apparatus were well developed. $\mathrm{N}$, nucleus; $\mathrm{Ng}$ neurosecretary granule. $\times 9000$ 


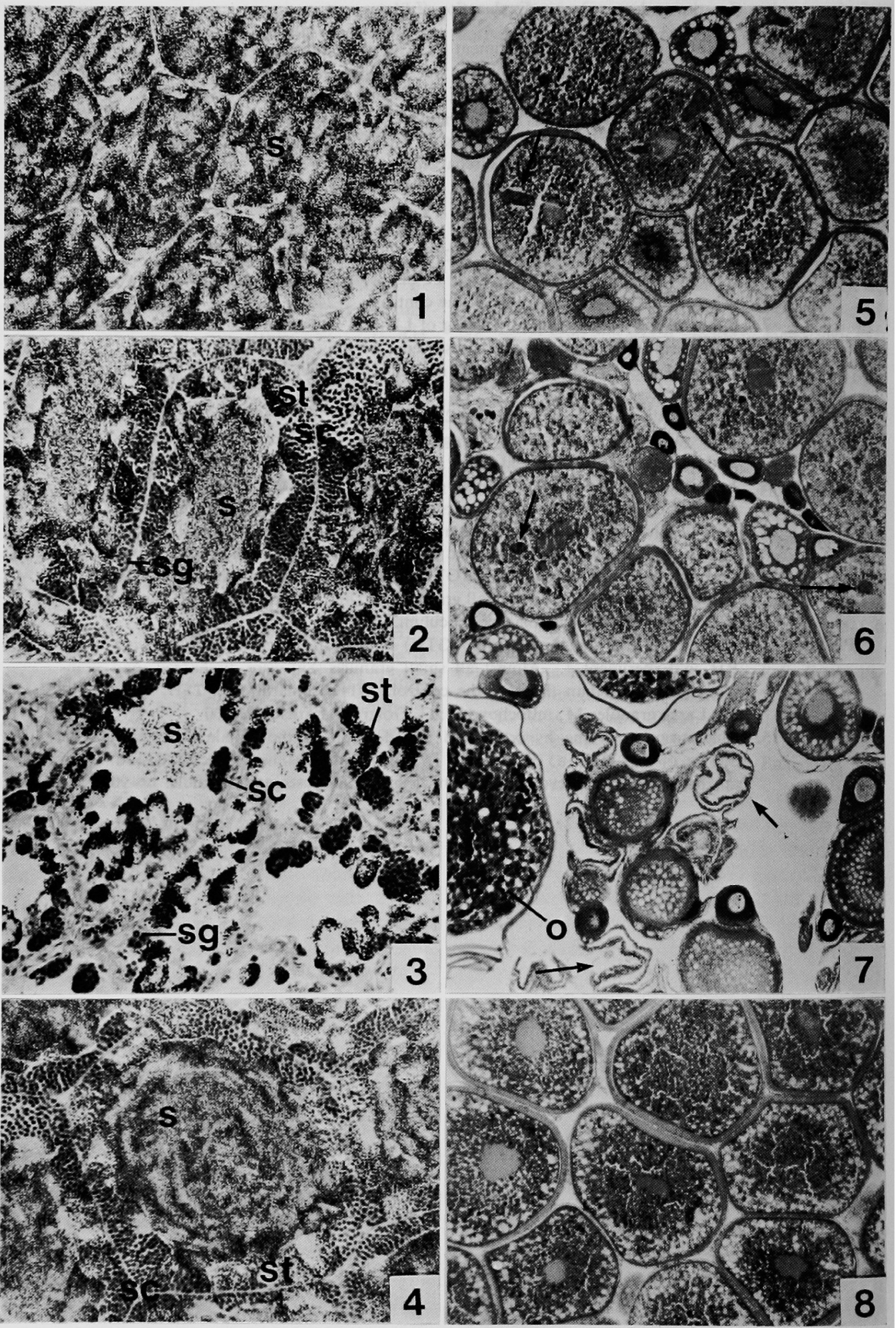




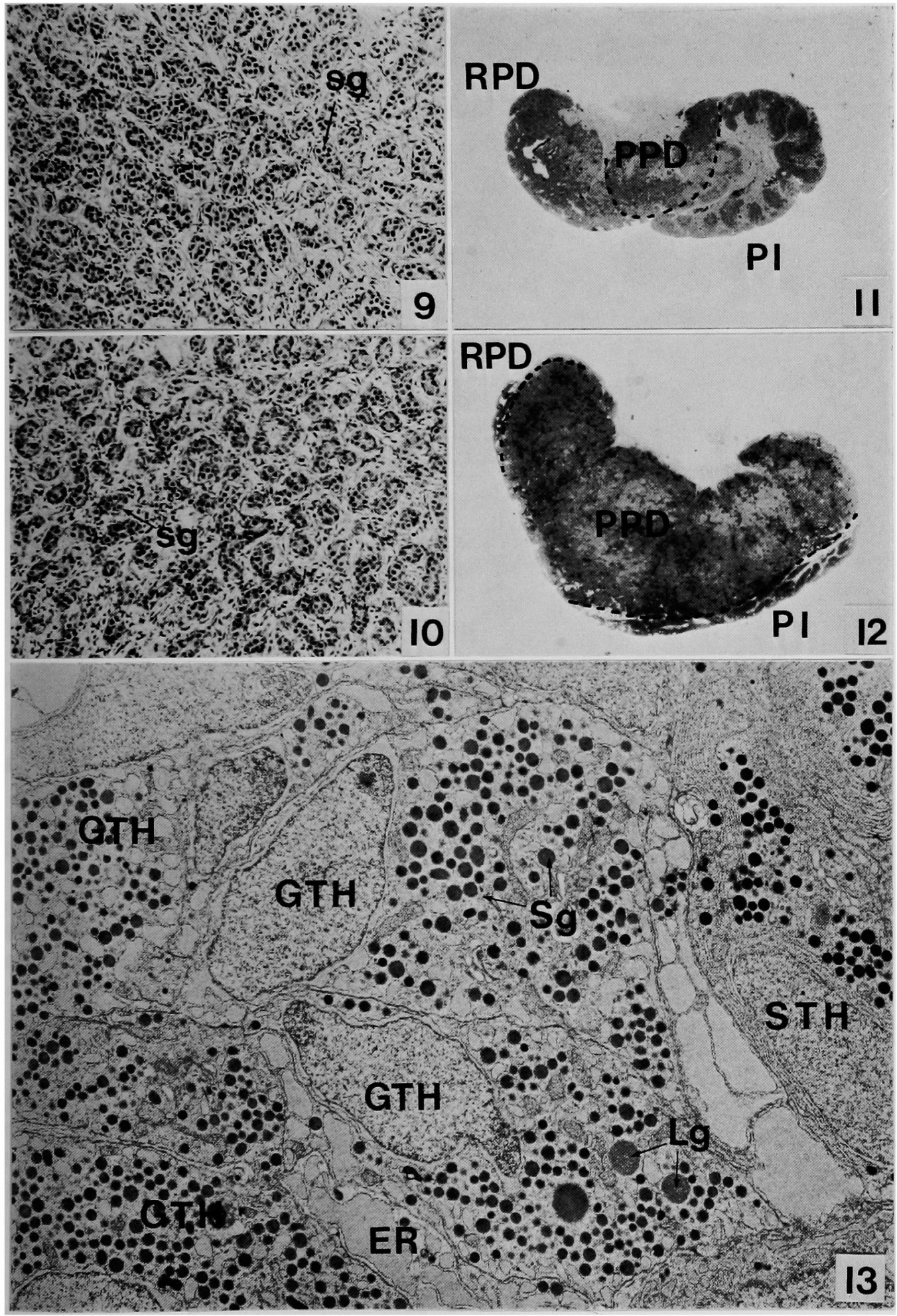




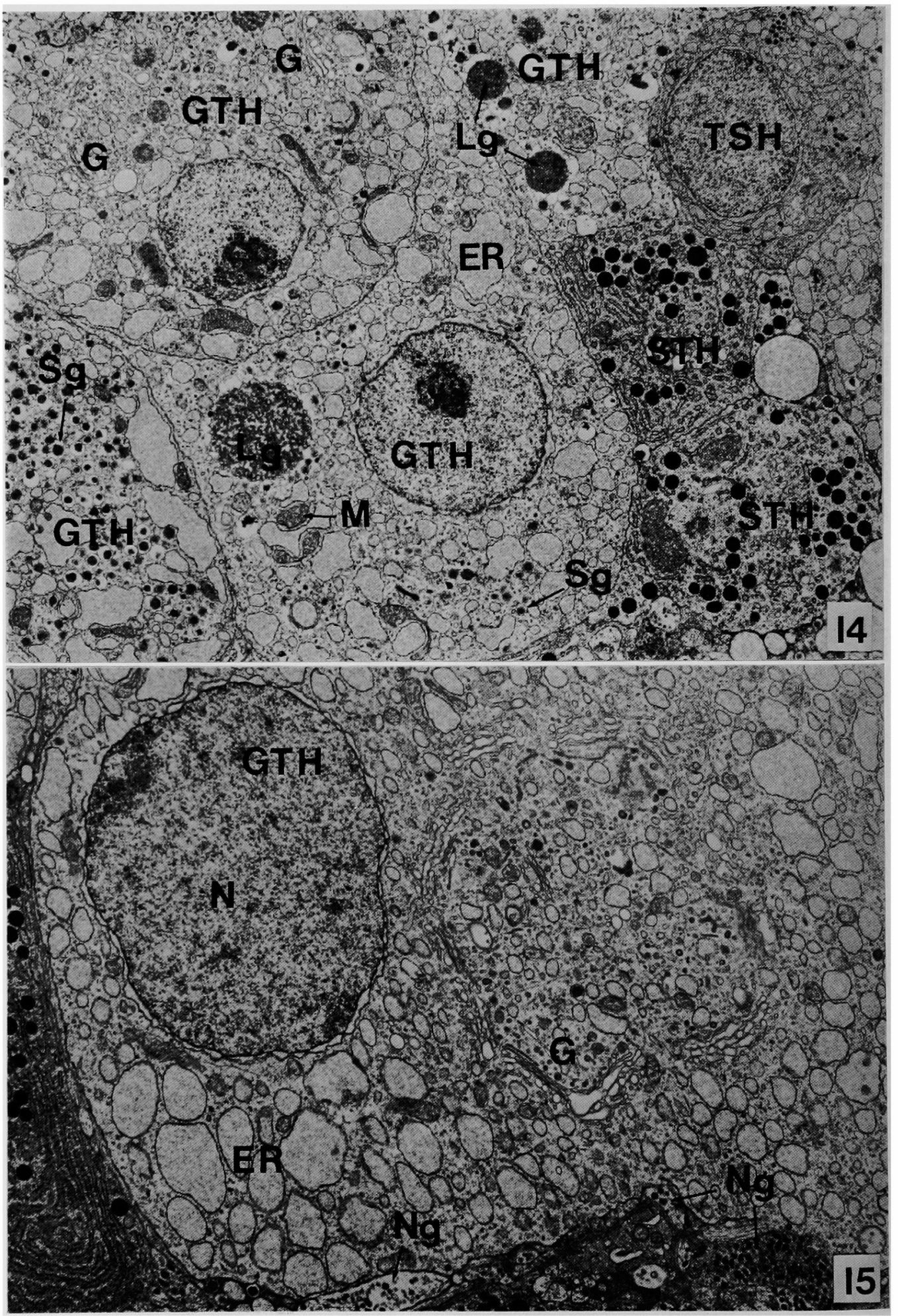

